\title{
THE BLOOD SUPPLY OF THE SPINAL CORD*
}

\author{
A Critical Vascular Zone in Spinal Surgery \\ G. F. Dommisse, Pretoria, South Africa \\ From the Department of Orthopaedics, University of Pretoria
}

Paraplegia following operations for the correction of scoliosis has been reported in slightly less than 1 per cent of 10,000 operations recorded by the Scoliosis Research Society of North America (MacEwen 1972). After operations for the correction of severe fixed curves in the adult the incidence is higher. In 1970 Dommisse and Enslin recorded four cases (6 per cent) in a series of sixty-eight operations for scoliosis in which a one-stage procedure for circumferential spinal osteotomy as described by Hodgson (1966) was performed. Three occurred between T.5 and T.9, in only eighteen operations on that region of the spine. The factors responsible for the disaster were ill-understood, and in the small series quoted the high incidence was totally unacceptable. Ischaemia was considered a possible cause, and accordingly an investigation into the normal blood supply of the human spinal cord was instituted. For the purpose of the investigation a "critical vascular zone of the spinal cord" was postulated and sought.

The literature on the subject was extensively reviewed and a number of interesting facts were exposed. Firstly, there is a lack of unanimity among different reports, which is disconcerting. Suh and Alexander (1939) observed that "much of what has been written in the past forty years about the circulation of the spinal cord is either inaccurate or incomplete." Although their statement is no longer necessarily valid, there remains a number of contentious issues attributable in part to the variations in the techniques of study employed. Secondly, the normal spinal cord enjoys little if any reserve of blood supply. Woollam and Millen (1958) recalled that the principles on which the vascular architecture of the spinal cord is organised had been summarised by Feeney and Watterson in 1946: "There exists a very close relationship between the metabolic requirements of the nervous tissue and the final distribution of intraneural vessels in the adult, a relationship which functions in such a way as to provide the nervous system with a blood supply just adequate for its minimal needs." In other words, wrote Woollam and Millen, "Man has just as much nervous system as he can supply with oxygen and no more." Thirdly, it is established that the central perforating arteries of the cord and the pial vessels which supply the cord are end-arteries in the sense that there are no anastomoses between their capillary beds (Bolton 1939, Turnbull 1971). Each is responsible for the supply of a specific part of the cord, and although a degree of overlap occurs, capillary anastomosis between zones does not take place. Fourthly, it is known that during the course of anterior surgical approaches to the spine, ligation of numbers of segmental vertebral arteries (commonly referred to as "intercostal arteries" in the thoracic region and "lumbar arteries" in the lumbar region) may be carried out with relative safety provided precautions are observed. Dwyer (1972) has ligated three to sixteen segmental arteries in 127 operations, without neurological loss. Hodgson (1972) had "a single case only in more than 100 operations" in which neurological deficit could have been due to this factor. He advised special caution at the tenth thoracic level, where the artery of Adamkiewicz commonly occurs.

\footnotetext{
* Based on a thesis presented in 1972 to the Faculty of Medicine in the University of Cape Town for the degree of Master of Surgery. Supported in part by a grant from the Medical Research Council of South Africa, and by the University of Pretoria.
}

vol. 56 B, NO. 2, MAY 1974 


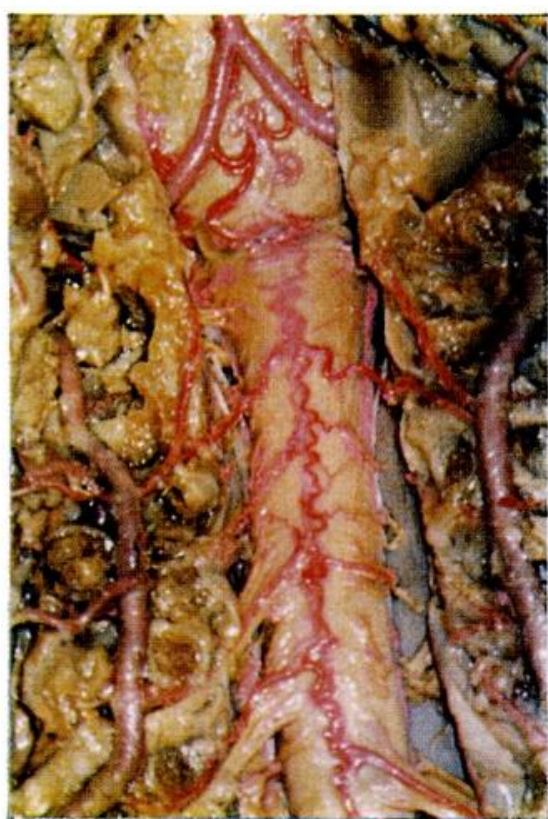

Fig. 1

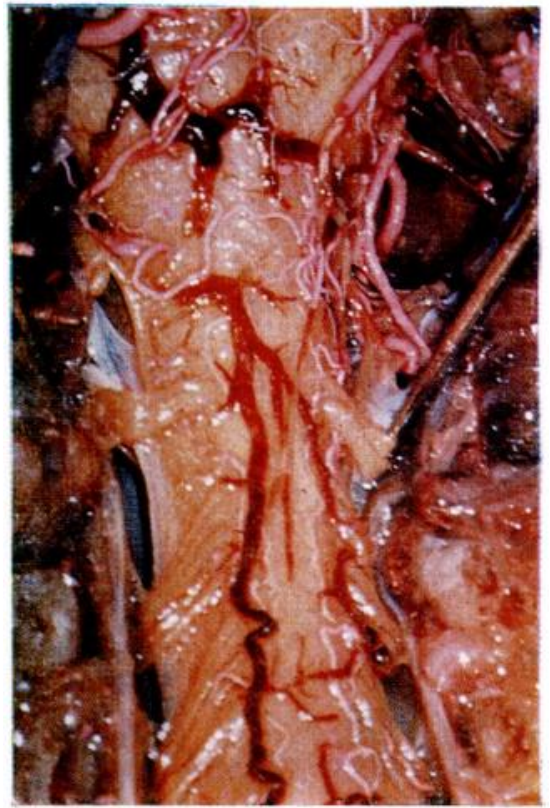

FIG. 2

Figure 1-A dissection from the front showing the anterior median longitudinal arterial trunk in the cervical region of the cord. Medullary feeder arteries from the vertebral artery are seen at the C.2 and C.6 levels on the left side of the dissection and at the C.2, C.4 and C.5 levels on the right side. Proximally the anterior spinal arteries arise from the vertebral arteries close to the basilar artery. Cadaver 3208. ( $\times 9$.) Figure 2-A dissection from the back showing the postero-lateral longitudinal trunks of the cord at proximal cervical level where they arise from the posterior inferior cerebellar arteries, and meander distally over and under cover of the posterior nerve rootlets. The dark, tortuous channel in the middle of the field is the posterior longitudinal vein. Cadaver 3254. $(\because 12$.

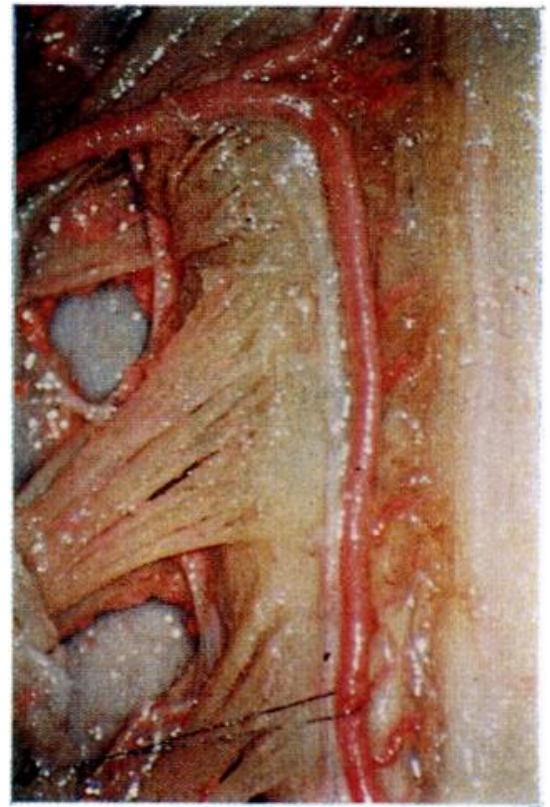

FIG. 3

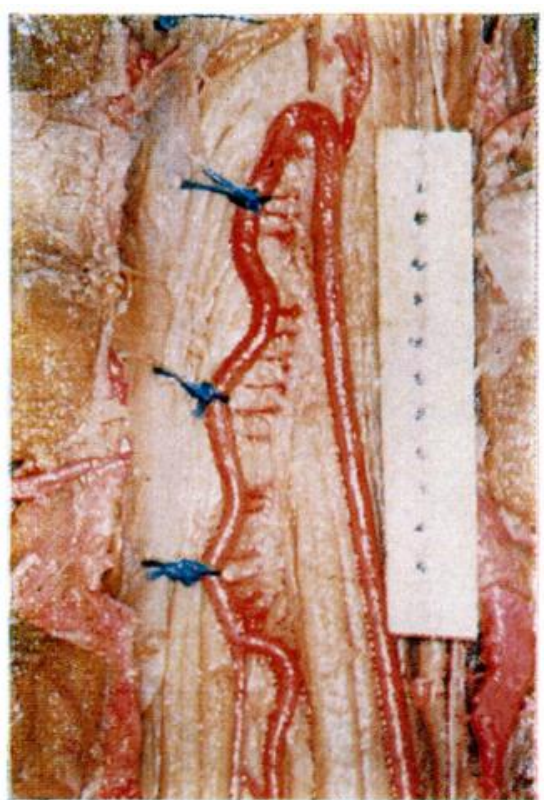

Fig. 4

Figure 3-Showing the central perforating arteries of the median sulcus at the C.7, C.8 and T.1 segmental levels. The diameter of the monofilament suture in the lower part of the field is $22 \mu$ (No. 10 zero). Figure 4-Showing the same arteries at T.12 and L.1 levels. The indicator is marked in millimetres and the stay sutures are $200 \mu$ in diameter. Fifteen medullary feeder vessels can be counted over a span of 1 centimetre. Cadaver 3447. $(\times 18$. 


\section{MATERIAL AND METHODS}

There were three separate methods of study: 1) a micro-dissection study of the vessels of the spine and spinal cord in thirty-five cadavers; 2) a radiological study of the spinal column in fifty healthy individuals aged from one and a half to sixty-eight years; and 3) a physical study of the macerated spinal column in six adult cadavers.

Micro-dissection studies-The dissections were pursued to arteriolar level, but the pre-capillaries and capillaries (in which the lumen is less than $20 \mu$ ) were excluded. The dissections were conducted with the spinal cord in situ. There were twenty-seven full-term foetal and neonatal cadavers, one infantile (eighteen months), one juvenile, two adolescent and four adult cadavers in the series. The specimens were prepared by means of an intra-arterial injection of latex delivered via the femoral artery at pressures which varied from 300 to 1,200 millimetres $\mathrm{Hg}$. In each case a small amount of dilute ammonia ( 2 to 3 cubic centimetres) preceded the injection in order to promote the flow. The entire circulatory system including the venous channels of a number of specimens was filled, while in others the arteries were more completely satisfied than the veins. The pressure of delivery and the resistance offered by the vessel walls appeared to be the determining factors. The binocular surgical microscope was used for all dissections at magnifications which varied from 10 to 40 times. In the adult cadavers the optimal magnification proved to be 10 times, while in the foetal and neonatal cadavers magnifications of up to 25 times were commonly used.

Radiological studies-In the radiological study of the spinal columns of fifty normal individuals, whose ages ranged from eighteen months to sixty-eight years, the width of the interpeduncular space was used as the index of measurement, and a reasonably accurate assessment of the relative widths of the spinal canal of the thoracic and lumbar vertebrae was obtained.

Study of macerated spinal column - In the study of the macerated spinal columns of six adult cadavers, a Vernier scale was used for an accurate measurement of the antero-posterior and lateral diameters of the canal of the thoracic and lumbar vertebrae.

\section{PRINCIPLES AND PATTERNS OF THE CIRCULATION OF THE SPINAL CORD}

The principles that govern the blood supply of the cord are constant, while the patterns vary with the individual. Some of the principles are as follows.

Dependence on three vessels-The cord is totally dependent upon three longitudinal arterial trunks or channels. Each of these is continuous and each extends from the medulla oblongata to the conus medullaris. They are the anterior median longitudinal arterial trunk situated over the median sulcus (Fig. 1) and a pair of postero-lateral trunks which ramify between and are partly obscured by the emerging posterior nerve rootlets (Fig. 2).

Relative demands of grey matter and white matter-The metabolic demands of the grey matter are greater than those of the white matter (Sokoloff 1961, Stephens and Stilwell 1969), and in the former the capillary networks are more numerous (Turnbull 1971). Accordingly, the longitudinal arterial trunks are greatest in the cervical and lumbar regions where the ganglionic enlargements occur, and the central perforating branches of the anterior median arterial trunks are larger (up to $200 \mu$ in diameter), and more numerous ( 5 to 8 per centimetre and 5 to 12 per centimetre respectively in the cervical and lumbar regions (Figs. 3 and 4)). By contrast, the perforating arteries of the thoracic cord (Fig. 5) are with few exceptions too small to be filled by the injection material used in this series and are of arteriolar or lesser size.

Medullary feeder arteries of the cord-The medullary feeders, commonly labelled "radicular arteries", reinforce the longitudinal arterial channels at various levels (Figs. 9 and 10). There were eight anterior and twelve posterior feeders per average cadaver in the series, and the numbers were the same in all age groups. There was a variability of from two to seventeen anterior and six to twenty-five posterior feeders, and the figures for the anterior group coincided with those of several others, notably Kadyi (1889), Suh and Alexander (1939) and Woollam and Millen (1958).

VOL. 56 B, NO. 2, MAY 1974 


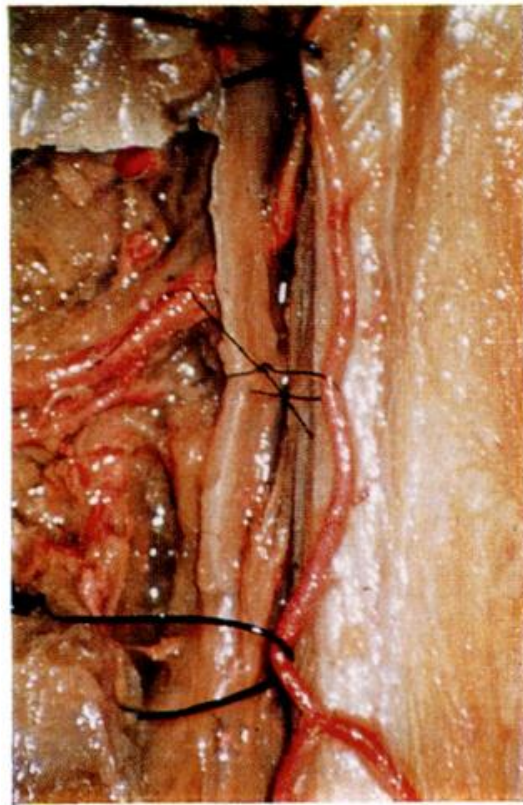

FIG. 5

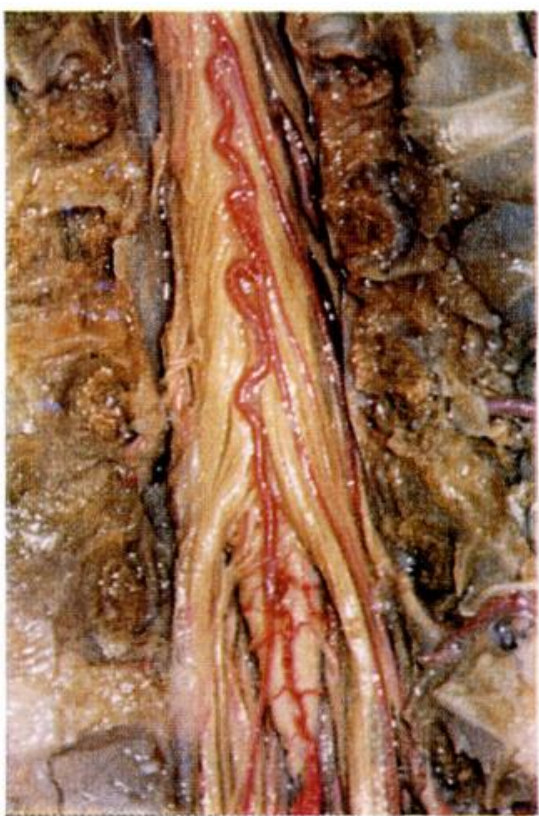

FIG. 6

Figure 5-Showing the central perforating arteries of the median sulcus at the T.5 and T.6 segmental levels. The upper and lower monofilaments are $100 \mu$ in diameter. Only three small medullary feeders are visible. Cadaver 3447. ( 18.) Figure 6-Showing, in the lower part of the photograph, bilateral communications between the anterior and the postero-lateral longitudinal arterial trunks at the level of the conus medullaris, seen here uncovered by nerve roots. Cadaver 3208. ( . 9.)

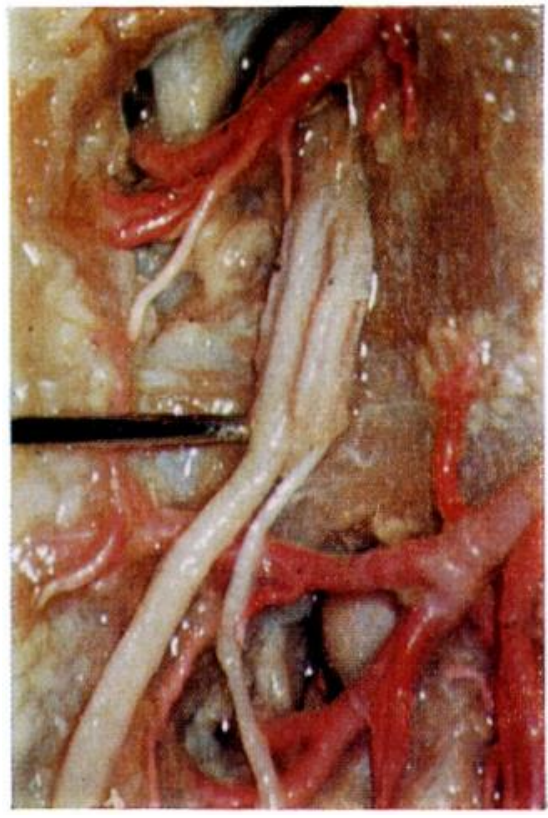

Fig. 7

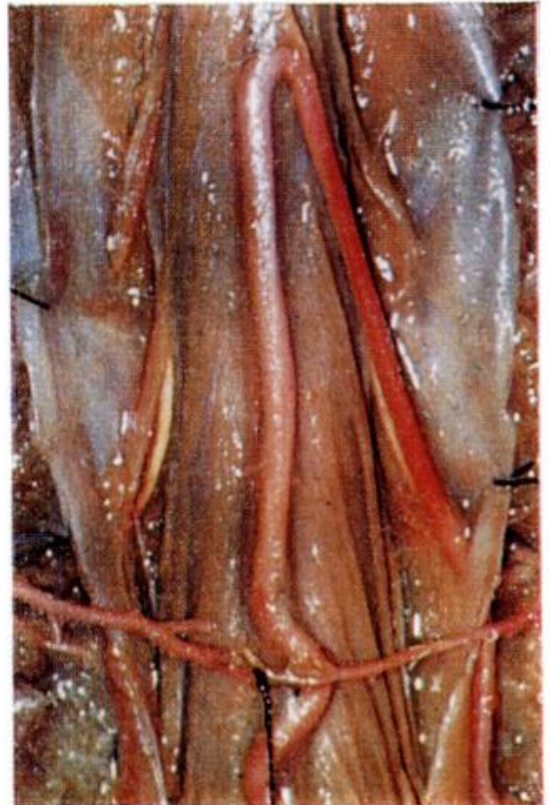

FIG. 8

Figure 7-Showing how the intervertebral foramen constitutes a "distribution point" for the segmental arteries, which divide here for the supply of extradural and intradural structures. The nerve root of L.1 and the posterior root ganglion of the L.2 nerve root are shown on the right. Cadaver 3212. (.12.) Figure 8-Showing the artery of Adamkiewicz. here present at T.11 level and entering the subdural space together with the nerve root. The transverse anastomotic arterial arcade is crossing from left to right in the extradural space. Cadaver 3185 . ( 18.) 
In the neck the vertebral arteries supply 80 per cent of the medullary feeders, the deep cervical and the superior intercostal supplying the remainder, with an occasional contribution from the ascending cervical artery. In the thoracic and lumbar areas the aortic segmental arteries (the "intercostal" and "lumbar" arteries) are the source of supply. In the sacral region the lateral sacral arteries are significant, as well as the fifth lumbar, the ilio-lumbar and the middle sacral arteries.

When comparing the vessels of adults and full-term foetuses, it was the similarity rather than the differences which characterised the study. Whereas the average numbers and placings were identical, the average size of the adult vessels was only double that of the foetal. By contrast, the cord was four to five times greater in length and three to four times greater in cross-section.

Supplementary sources of blood supply of the spinal cord-An important source of arterial supply is found at both proximal and distal extremities. The former is served by the anterior and posterior spinal arteries which arise from the vertebral and the posterior inferior cerebellar arteries respectively (Figs. 1 and 2). The latter is served by a bilateral set of communicating vessels at the conus medullaris (Fig. 6), connecting the anterior to the posterior arterial systems and reinforced in at least 40 per cent of cadavers by sacral medullary feeders which arise from the lateral sacral arteries and which accompany the distal roots of the cauda equina to the cord.

Romanes (1965) subscribes to the theory of a postero-anterior direction of flow in these vessels; others offer a contrary opinion. It would seem likely that the direction is reversible and the volume adjustable in response to the metabolic demands.

The segmental arteries of the vertebral column-There is a pair of segmental arteries at every intervertebral level for the supply of extraspinal and intraspinal structures, including the spinal medulla. The thoracic and lumbar segmental arteries arise from the aorta. In the cervical region they arise from the vertebral arteries, and from the branches of the costo-cervical and thyro-cervical trunks. An interesting additional source is the ascending pharyngeal branch of the external carotid artery in approximately 60 per cent of cadavers. In the sacral region the lateral sacral arteries, and to a lesser extent the fifth lumbar, ilio-lumbar and the middle sacral arteries, supply segmental vessels.

The "distribution point" of the segmental arteries-The segmental arteries divide into numerous branches at the intervertebral foramen, which may with good reason be termed "the distribution point" (Fig. 7). En route to the foramina they supply numerous nutrient vessels to the vertebrae and a rich anastomotic network on the surfaces of the vertebral bodies and on the transverse processes and pedicles. These anastomoses are between ipsi- and contra-lateral arteries. A second anastomotic network of a similar nature and between the same arteries is found within the spinal canal in the loose connective tissue of the extra-dural space. It occurs at all levels and with greatest concentration in the cervical and lumbar regions.

The rich anastomotic channels offer "alternative pathways" for the arterial flow (Lazorthes, Gouaze, Zadeh, Santini, Lazorthes and Burdin 1971) and serve to maintain the flow under conditions of stress. Undoubtedly it is owing to their presence that the spinal cord circulation is preserved after the ligation of segmental arteries.

The artery of Adamkiewicz-Also known as the arteria radicularis anterior magna, this is the largest of the feeders of the lumbar cord (Fig. 8). It occurs on the left side in 80 per cent of cases, at between T.7 and L. 4 levels, with a predilection for T.9 to T.11 levels. In this series it was accompanied by at least one other feeder in thirty-four out of thirty-five cords; it was matched in size by a cervical feeder in the majority of cases.

This artery was ligated by Di Chiro, Fried and Doppman (1970) in a number of rhesus monkeys without complication, but it was noted that paraplegia developed when the anterior median longitudinal artery of the cord was tied at a level distal to the junction with the artery of Adamkiewicz. It is clear that the anterior longitudinal arterial channel of the cord is crucial,

VOL. 56 B, No. 2, MAY 1974 
rather than any single medullary feeder. It is equally clear that preservation of this particularly large feeder will not ensure the continued satisfactory circulation of the spinal cord.

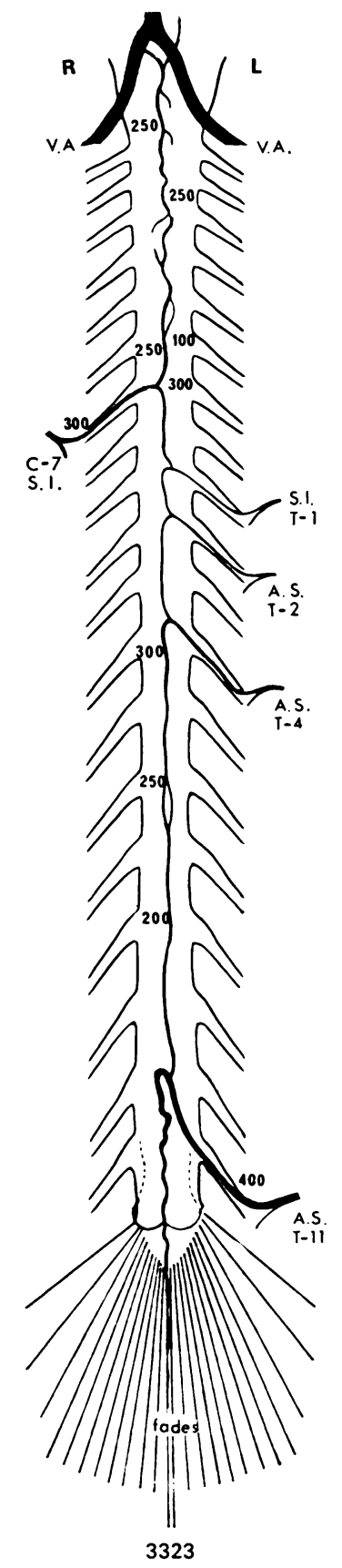

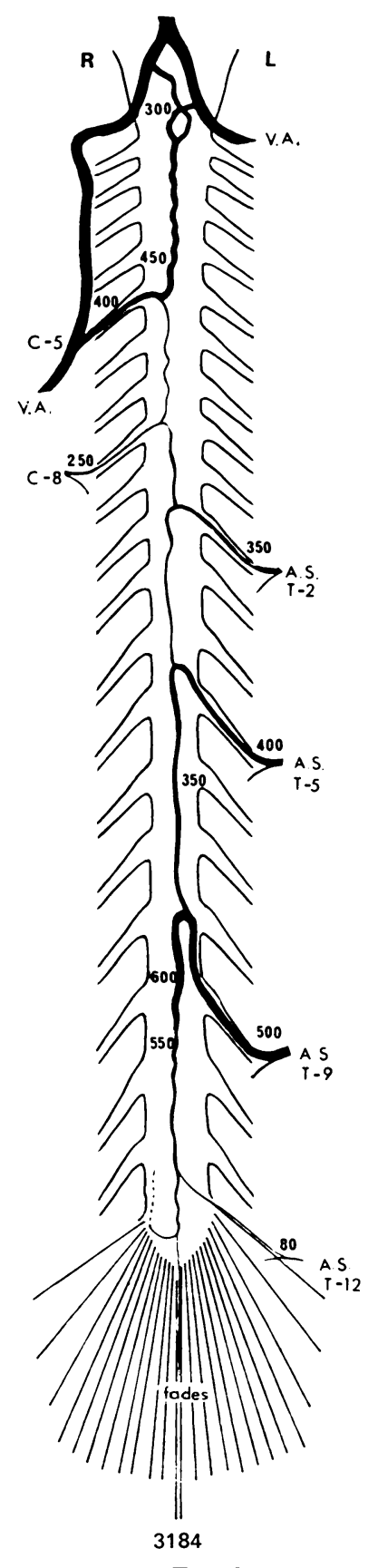

Fig. 9

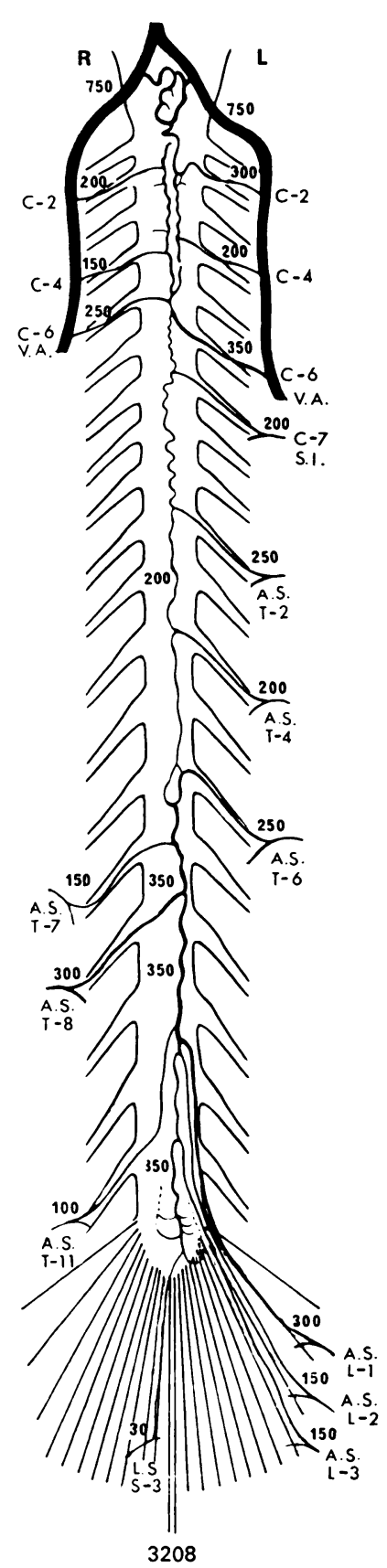

3208

Diagrams of the anterior median longitudinal arterial trunks of three cadavers, showing the size, number and situation of the medullary feeder arteries. The artery of Adamkiewicz occurs on the subject's left side at T.11 and T.9 levels in Cadavers 3323 and 3184 respectively and on the right side at T.8 level in Cadaver 3208. There are seventeen medullary feeders in Cadaver 3208, the greatest number in the series.

While it would be unwise to belittle the importance of the artery of Adamkiewicz, it would appear of greater practical value to protect and preserve each contributory artery as far as this is surgically possible. 
Variability of the patterns of supply of the spinal cord-The variability of patterns was a striking feature of the dissections, yet there was at all times an absolute conformity with the principle

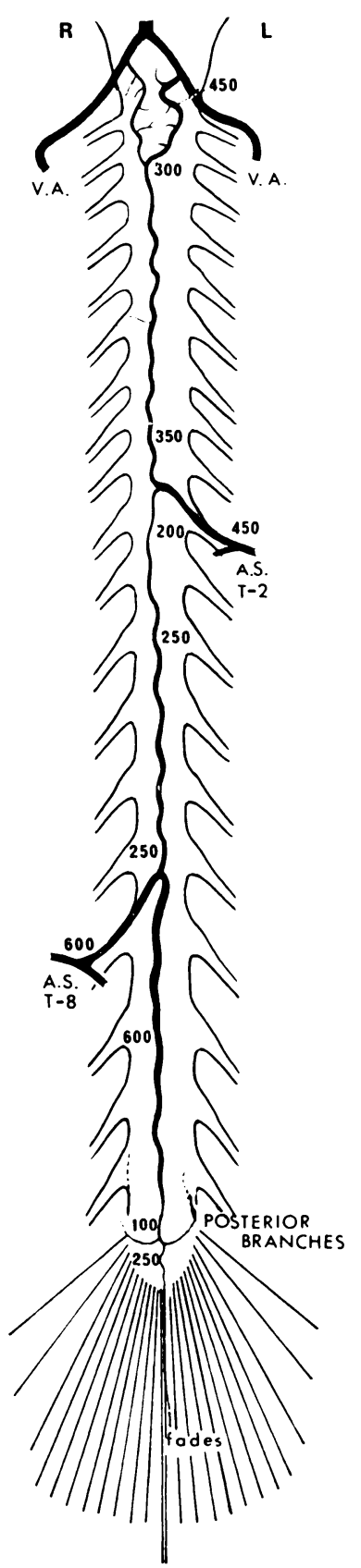

3247

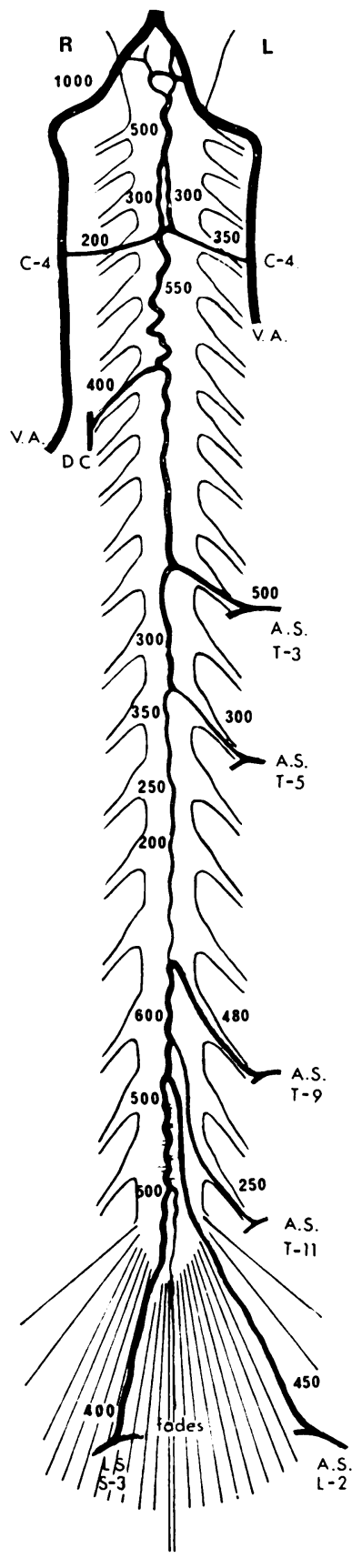

3212

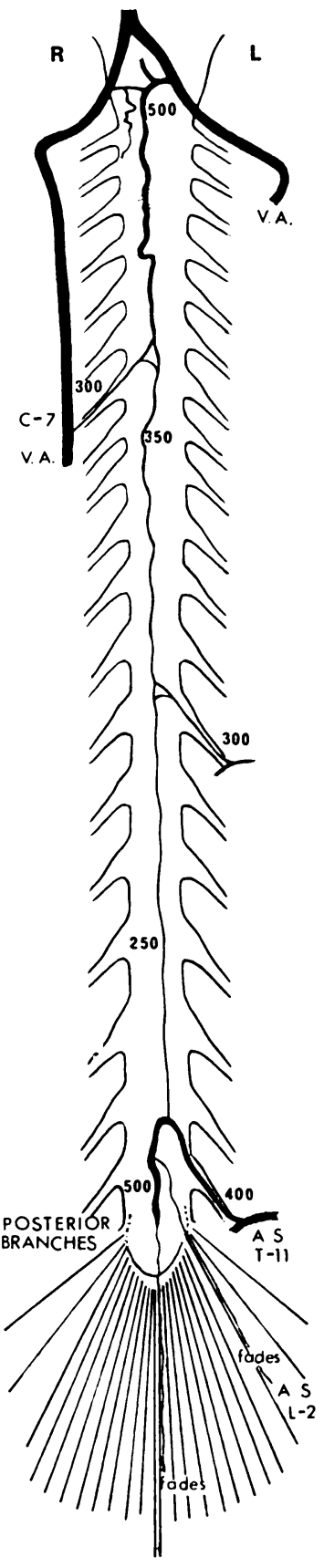

3211

Fig. 10

Diagrams of the anterior median longitudinal arterial trunks of three further cadavers. There are only two medullary feeders, at T.2 and T.8 in Cadaver 3247, the smallest number in the series. Contributions to the longitudinal arterial trunk are made at the proximal and distal extremities of the cord.

of a rich supply for the cervical and lumbar enlargements and a less rich supply for that part of the thoracic cord which extended from approximately T.4 to T.8 or 9 vertebral levels. 
Diagrammatic representations of the anterior arterial patterns of six cadavers serve to illustrate the variations (Figs. 9 and 10). A similar variability of pattern was discernible at posterior level, and there was no sort of correlation between the anterior and the posterior patterns. The concept of an average pattern was therefore abandoned by the author.

Direction of flow in the blood vessels of the spinal cord-It appears fruitless to discuss the spinal cord circulation in terms of direction of flow. Numerous reports are at variance, and they vary as the techniques employed in the studies. The three longitudinal arterial channels should rather be regarded as the innermost portion of a complicated "arterial circle" which although more extensive and more complicated than the circle of Willis at the base of the brain, functions in terms of identical principles and permits reversal of flow and alterations in the volume of flow in response to the metabolic demands of the moment.

The pattern is complicated by the fact that the "inner arterial circle" is surrounded by at least two "outer arterial circles", the first of which is situated in the extra-dural space and the second in the extravertebral tissue planes. The outer arterial circles display in abundance that degree of anastomosis which is lacking in the inner circle, and it is by virtue of their presence that the spinal cord enjoys reserve sources of supply in the event of pathological interruption or surgical ligation of medullary feeders. A warning note must however be sounded, namely, that the extent of the anastomoses varies, and that at irregular levels they are absent.

It will be observed that although the sources of supply of the outer arterial circles of the spinal cord are numerous and are interspaced at various levels from basi-occiput to sacrum, the "outlet points" are limited to the perforating sulcal arteries and the pial arteries of the cord. The control of the circulation of the cord is in terms of physiological mechanisms beyond the scope of this presentation.

\section{THE WIDTH OF THE SPINAL CORD}

The spinal canal is of variable width and shape throughout its length. In the sacral region it is flattened from before backwards and there are wide tunnels for the passage of the roots of the cauda equina. In the cervical region and at the lumbar enlargement it is capacious, with a large lateral extension for each of the roots of the brachial and lumbar plexuses. In the thoracic region the contrast is striking, for it is here that the canal is narrowest and assumes the rounded or semi-elliptic shape of "natural intention". It is consistently narrowest in that part of the vertebral column which extends from T.4 down to T.8 or 9 levels (Table I), and occasionally down to T.10 or T.11. The narrow zone of the spinal canal corresponds almost exactly with that part of the cord to which the blood supply is least profuse.

The examination of six macerated vertebral columns served to confirm the above radiological findings (Table II).

\section{PARAPLEGIA COMPLICATING SPINAL OPERATIONS}

As already mentioned Dommisse and Enslin have reported four cases of paraplegia in a series of sixty-eight procedures. Three occurred between T.5 and T.9, yet only eighteen operations were done in this region. There were fifty operations below the T.10 level, with only one case of paraplegia, and this in a patient with a partial lesion before the operation due to congenital spina bifida.

The above figures serve to emphasise the surgical hazards at the "critical zone of the spinal cord" which extends from T.4 to about the T.9 level. They indicate also the relative safety of surgical procedures below the level of T.10. The tenuous blood supply of the cord and the limited capacity of the spinal canal are demonstrable factors.

Dwyer, in a recent personal communication, refers to four cases of total paraplegia 
TABLE I

The Critical Narrow Zone of the Spinal Canal

\begin{tabular}{|c|c|c|c|c|c|c|c|c|c|c|c|c|c|c|c|c|c|c|c|}
\hline $\begin{array}{l}\text { Case } \\
\text { number }\end{array}$ & $\begin{array}{c}\text { Age } \\
\text { years })\end{array}$ & Sex & T.1 & T.2 & T.3 & T.4 & T.5 & T.6 & T.7 & T.8 & T.9 & T.10 & T.11 & T.12 & L.1 & L. 2 & L.3 & L.4 & L.5 \\
\hline 1 & 4 & Male & 21 & 19 & 17 & 16 & $15 \cdot 5$ & 15.5. & 16 & 16 & 16 & 17 & 17 & $17 \cdot 5$ & 20 & 20 & 20 & 22 & 24 \\
\hline 2 & 14 & Female & 23 & 20 & 18 & $17 \cdot 5$ & 17 & 16.5 & 16 & 16.5 & 17 & 18 & 20 & & Rota & ated & & 22 & 25 \\
\hline 3 & 15 & Female & 23 & 22 & 20 & 18 & 18 & 19 & 19 & 19 & 19 & 19 & 20 & 23 & Rota & ated & & 26 & 31 \\
\hline 4 & 9 & male & 21 & 18 & 17 & 17 & 17 & 17 & 18 & 18.5 & 19 & 19 & 19 & 22 & 22 & $22 \cdot 5$ & 23 & 25 & 27 \\
\hline 5 & 32 & Female & 22 & 22 & 17 & 16 & 16 & 15 & 15 & 15.5 & 16 & 17 & 18 & $21 \cdot 5$ & 23 & 25 & 26 & 26 & 30 \\
\hline 6 & 37 & Male & 27 & 23 & 21 & 19 & 19 & 19 & 18 & 18.5 & 19 & 19 & 20 & 25 & 27 & 27 & $27 \cdot 5$ & 29 & 34 \\
\hline 7 & 11 & Female & 21 & 18 & 17 & 16.5 & 16.5 & 16 & 15.5 & 16.5 & 17 & 17 & 18 & 21 & 22 & 22 & 23 & 24 & \\
\hline 8 & 3 & Female & 21 & 18 & 17 & 16 & $15 \cdot 5$ & 155 & 16 & 17 & $17 \cdot 5$ & 18 & 18 & 20 & 21 & 21 & 21 & 21 & 27 \\
\hline 9 & $1 \frac{1}{2}$ & Male & 18 & 18 & 15 & 14 & 15 & 15 & 15 & 15 & 15 & 15 & 16 & 18 & 19 & 19 & 19 & 21 & 25 \\
\hline 10 & 3 & Female & 23 & 21 & 20 & 19 & 19 & 18.5 & 18.5 & 19 & 20 & 21 & 22 & 25 & 26 & 26 & 26 & 26 & 32 \\
\hline 11 & 42 & Male & ? & 22 & 21 & 21 & 21 & 21 & 22.5 & 23 & 24 & 25 & 28 & 32 & 32 & 30 & 31 & 33 & 34 \\
\hline 12 & 11 & Fem & 23 & 20 & 19 & 18 & 17 & 17 & 17 & 18 & $18 \cdot 5$ & 19 & 21.5 & 25 & 25 & 25 & 26 & 26 & \\
\hline 13 & 11 & Male & 24 & 20 & 19 & $17 \cdot 5$ & 17 & 165 & 16.5 & 16.5 & 16.5 & 16.5 & 17 & 19 & 21 & $22 \cdot 5$ & 24 & 25 & 27 \\
\hline 14 & 2 & N & $?$ & $?$ & 20 & 19 & 19 & 19 & 18.5 & 19 & 20 & 20 & 21 & 26 & 26 & $26 \cdot 5$ & 27 & $27 \cdot 5$ & 30 \\
\hline 15 & 68 & Male & 23 & 22 & 21 & 20 & 18.5 & 19 & $19 \cdot 5$ & 19 & 19 & 19 & 20 & $23 \cdot 5$ & 25 & 25 & 28 & 31 & ? \\
\hline 16 & 6 & Female & & & $19 \cdot 5$ & $18 \cdot 5$ & 18 & 18 & 18.5 & 19 & 19.5 & 20 & $21 \cdot 5$ & & $26 \cdot 5$ & 28 & 30 & 34 & 40 \\
\hline 17 & 13 & Male & $?$ & $?$ & 18 & $17 \cdot 5$ & 17 & 165 & 17 & $17 \cdot 5$ & $17 \cdot 5$ & $18 \cdot 5$ & 20 & $22 \cdot 5$ & 23 & 24 & 24 & 27 & 35 \\
\hline 18 & 41 & Iale & 25 & 21.5 & $21 \cdot 5$ & 21 & 20 & 21.5 & 21 & 20 & 20 & 20 & 21 & 26 & 25 & 27 & 27 & 29 & \\
\hline 19 & 12 & $\mathrm{Ma}$ & $?$ & ? & 18.5 & 18 & 17.5 & 17.5. & 17.5 & $17 \cdot 5$ & 18.5 & 21 & 24 & 26 & $26 \cdot 5$ & 25 & 25 & $23 \cdot 5$ & \\
\hline 2 & 33 & Female & $?$ & 20 & 19 & $17 \cdot 5$ & 17 & 17 & 17.5 & 17.5 & 19 & 20 & 23 & 28 & 28 & 27 & 27 & 31 & 32 \\
\hline 2 & 4 & $\mathrm{Ma}$ & 22 & 21 & 18 & 17 & 17 & 17 & 16 & 16 & 17 & 17 & 17 & 18 & 20 & 22 & 25 & 26 & 35 \\
\hline 2 & 3 & & 23 & 20 & 18 & 17 & 16 & 165. & 16 & 16 & 16 & 17 & 18 & 2 & 21 & 22 & 23 & & 30 \\
\hline 2. & 4 & & 21 & 19 & 17 & 17 & 18 & 18 & 18 & 19 & 19 & 20 & & & 25 & & & & \\
\hline 2 & & & 22 & 22 & 20 & 18 & 17 & 17 & 17 & 17.5 & 18 & 19 & 22 & 25 & 2 & 28 & 28 & & \\
\hline 2 & 4( & & 21 & 20 & 19 & 19 & 19 & 19 & 18 & 18 & 18 & 19 & 2 & & 24 & 24 & 26 & & \\
\hline & & & 21 & 18 & 17 & 16 & 15 & 16 & 16 & 17 & $17 \cdot 5$ & 18 & 19 & 2 & 2 & 21 & 22 & & \\
\hline 2 & 42 & & 23 & 21 & 21 & 19 & 18 & $18 \times 5$ & 19 & 21 & 22 & 23 & 25 & 2 & 28 & & 28 & & \\
\hline & & & 25 & 21 & 19 & 19 & 19 & 18 & 18.5 & 19 & 20 & 20 & 21 & 2 & 25 & 25 & 23 & & \\
\hline 2 & 17 & Fem & 23 & 20 & 17 & 17 & 16 & 163 & 17 & 18.5 & 20 & 20 & 20.5 & $21 \cdot 5$ & $22 \cdot 5$ & 24 & 24 & & \\
\hline & & & $22 \cdot 5$ & 20 & 18 & $16 \cdot 5$ & $16 \cdot 5$ & 17 & 18 & 19 & 19 & 20 & 21 & 24 & Rota & ated & 24 & & \\
\hline 3 & 17 & & 26 & 22 & 19 & 18 & 17 & 17 & 17 & 17 & $17 \cdot 5$ & 18.5 & 20 & 24 & 27 & 27 & 27 & & \\
\hline & & & 26 & 25 & 22 & $21 \cdot 5$ & 20 & 20 & 19 & 18.5 & 18 & 21 & 22 & & 28 & 27 & 28 & & \\
\hline 3. & 15 & & 24 & 21 & $19 \cdot 5$ & $18 \cdot 5$ & $17 \cdot 5$ & 16.5 & 17 & 18 & 18.5 & 18.5 & $20 \cdot 5$ & $22 \cdot 5$ & 24 & 24 & $24 \cdot 5$ & & \\
\hline & & & 27 & 23 & 21 & 20 & 20 & 20 & 21 & 21 & 21.5 & 22 & 23 & & 2 & 25 & 27 & & \\
\hline 3. & 30 & $\mathrm{Ma}$ & 32 & 26 & 23 & 22 & 20 & 20 & 20 & $19 \cdot 5$ & 20 & 22 & 22 & 2. & 28 & 28 & 29 & & \\
\hline & & & 26 & 22 & 19 & 18 & 17 & 17 & 16 & 17 & 16 & 17 & & & 2 & 26 & 26 & & \\
\hline 3 & 2 & $\mathrm{Ma}$ & 16 & 15.5 & 15 & 15 & 14 & 15 & 16 & 16 & 16 & 17 & 19 & 19 & 19 & 20 & 20 & & \\
\hline 3 & 15 & & 23 & 20 & 17 & 16 & 16 & 16 & 15 & 16 & 17 & 17 & 18 & & 21 & 21 & 22 & & \\
\hline 3 & 16 & & 22 & 19 & 17 & 16 & 15 & 15 & 15 & 16 & $17 \cdot 5$ & 19 & 21 & $21 \cdot 5$ & $22 \cdot 5$ & 26 & 27 & & \\
\hline 4 & & & 21 & 19 & $17 \cdot 5$ & 16 & $15 \cdot 5$ & 16 & $16 \cdot 5$ & 17 & 17 & 18 & 20 & & 22 & 22 & & 24 & 27 \\
\hline 41 & 4 & & 21 & 18 & 17 & $16 \cdot 5$ & 16.5 & 165 & 16 & 16.5 & 16.5 & 17 & 19 & 21 & 2 & 22 & 23 & 24 & 25 \\
\hline 42 & 17 & & & 19 & 18 & 15 & 16 & 16 & 18 & 18 & 18 & 18 & 20 & & 2 & 22 & 2. & & \\
\hline 4. & 12 & & & 20 & 18 & 17 & 17 & 16 & 17 & 17 & 17 & 17 & 18 & 20 & 22 & 23 & 23 & 6 & 31 \\
\hline & 36 & & & 21 & 18 & 18 & 17 & 18 & 18 & 18 & 18 & 18 & & & Ro & ated & & & 30 \\
\hline 4. & 12 & & 22 & 2 & 18 & 18 & 18 & 17 & 18 & 18.5 & 18.5 & 19 & 20 & & 23 & 24 & 26 & & \\
\hline 46 & 13 & & 25 & 20 & 18 & 18 & 17 & 17 & $17 \cdot 5$ & 18 & 18.5 & & $20 \cdot 5$ & & 25 & 25 & 27 & 27 & \\
\hline 47 & 30 & & 22 & 19 & 18 & $17 \cdot 5$ & 18 & 175 & 17 & 17 & 17 & 18 & 18 & 20 & $?$ & 22 & 22 & 25 & 27 \\
\hline 48 & 10 & & ? & $?$ & 20 & 18 & 18 & 1855 & 18.5 & 19 & 19 & & 21 & $21 \cdot 5$ & & 24 & 24 & 25 & \\
\hline 49 & 4 & & 25 & 20 & $18 \cdot 5$ & 17 & 18 & 18 & 18 & 18 & 18.5 & $18 \cdot 5$ & 21 & 22 & 2 & 22 & 22 & $22 \cdot 5$ & 23 \\
\hline 50 & 17 & Female & 22 & 18 & 17 & 17 & 16.5 & 16 & 16 & 16.5 & 17 & 18 & 19 & 24 & 24 & 24 & 23 & 23 & 25 \\
\hline
\end{tabular}

The width of the interpeduncular spaces of the thoracic and lumbar regions of the spine, expressed in millimetres, as determined radiographically in fifty healthy individuals of various age groups and of both sexes. Several cases of subclinical scoliosis are included in the series. The narrow zone of the spinal canal, indicated by a heavy horizontal line, extends from T.4 to T.8 level in the majority of cases, and includes the sixth thoracic vertebra in forty-nine of the fifty cases.

developing during the management of severe scoliotic deformity: in each case correction with traction preceded the fusion operation, and in each case the mechanical forces associated with the procedures were of equal magnitude at all levels. Post-mortem examination in one instance revealed "central necrosis of the cord extending over four to five segments and the anterior spinal artery still intact. The necrosis extended from T.5 to T.9 approximately, and almost the only recognisable anatomical structure was the anterior spinal artery." While it would be premature to draw conclusions from this report of a single case, it is nevertheless a 
TABLE II

The Antero-posterior and Lateral Dimensions of the Spinal Canal, Expressed in Millimetres, Mfasured in Six CaDavers

\begin{tabular}{|c|c|c|c|c|c|c|c|c|c|c|c|c|}
\hline \multirow{2}{*}{ Level } & \multicolumn{2}{|c|}{2806} & \multicolumn{2}{|c|}{2833} & \multicolumn{2}{|c|}{2751} & \multicolumn{2}{|c|}{ 2917A } & \multicolumn{2}{|c|}{2985} & \multicolumn{2}{|c|}{ 2917B } \\
\hline & Lat. & A-P. & Lat. & A-P. & Lat. & A. $-\mathbf{P}$ & Lat. & A-P. & Lat. & A-P. & Lat. & A-P. \\
\hline T.1 & $22 \cdot 7$ & $13 \cdot 8$ & $21 \cdot 3$ & 14.4 & $22 \cdot 3$ & $15 \cdot 0$ & $17 \cdot 8$ & $13 \cdot 7$ & $21 \cdot 7$ & 15.9 & $18 \cdot 2$ & $12 \cdot 8$ \\
\hline 2 & $20 \cdot 6$ & $14 \cdot 6$ & $18 \cdot 2$ & $13 \cdot 7$ & $18 \cdot 8$ & $14 \cdot 6$ & $15 \cdot 4$ & $13 \cdot 6$ & $19 \cdot 4$ & $15 \cdot 0$ & $16 \cdot 5$ & $12 \cdot 6$ \\
\hline 3 & $18 \cdot 7$ & $14 \cdot 6$ & $16 \cdot 5$ & $13 \cdot 6$ & $16 \cdot 5$ & $16 \cdot 3$ & $14 \cdot 4$ & $13 \cdot 5$ & $17 \cdot 7$ & $15 \cdot 1$ & $15 \cdot 7$ & $12 \cdot 8$ \\
\hline 4 & $17 \cdot 7$ & $14 \cdot 6$ & $14 \cdot 2$ & $13 \cdot 3$ & $15 \cdot 9$ & $15 \cdot 2$ & $14 \cdot 3$ & 12.5 & 16.0 & $14 \cdot 7$ & 15.0 & $13 \cdot 4$ \\
\hline 5 & $17 \cdot 7$ & $14 \cdot 2$ & $14 \cdot 6$ & $12 \cdot 9$ & $15 \cdot 1$ & $14 \cdot 1$ & $14 \cdot 0$ & $12 \cdot 0$ & $15 \cdot 4$ & $14 \cdot 5$ & $14 \cdot 1$ & 13.9 \\
\hline 6 & $17 \cdot 0$ & 13.9 & $14 \cdot 1$ & $13 \cdot 2$ & $14 \cdot 3$ & $14 \cdot 2$ & $14 \cdot 2$ & $11 \cdot 2$ & $15 \cdot 1$ & $14 \cdot 0$ & $14 \cdot 7$ & $13 \cdot 8$ \\
\hline 7 & $16 \cdot 7$ & $14 \cdot 1$ & $15 \cdot 3$ & $12 \cdot 2$ & $14 \cdot 2$ & $14 \cdot 2$ & 13.9 & $12 \cdot 2$ & $15 \cdot 3$ & $14 \cdot 4$ & $15 \cdot 2$ & $14 \cdot 2$ \\
\hline 8 & $16 \cdot 1$ & 13.6 & 14.4 & $13 \cdot 2$ & 14.9 & $14 \cdot 2$ & $15 \cdot 5$ & $12 \cdot 7$ & $16 \cdot 1$ & $14 \cdot 3$ & $15 \cdot 2$ & $13 \cdot 4$ \\
\hline 9 & 16.6 & 13.9 & $15 \cdot 2$ & $12 \cdot 3$ & $15 \cdot 0$ & $14 \cdot 5$ & $15 \cdot 0$ & $13 \cdot 1$ & $16 \cdot 8$ & $14 \cdot 5$ & $14 \cdot 7$ & $15 \cdot 4$ \\
\hline 10 & $17 \cdot 0$ & $13 \cdot 1$ & 15.0 & $11 \cdot 8$ & $15 \cdot 0$ & $14 \cdot 4$ & $17 \cdot 0$ & $13 \cdot 2$ & $17 \cdot 3$ & $14 \cdot 8$ & $15 \cdot 7$ & $13 \cdot 6$ \\
\hline 11 & $17 \cdot 3$ & $13 \cdot 6$ & $15 \cdot 4$ & 12.0 & $15 \cdot 3$ & $14 \cdot 8$ & $18 \cdot 3$ & $15 \cdot 0$ & $17 \cdot 1$ & $14 \cdot 9$ & $16 \cdot 0$ & $14 \cdot 3$ \\
\hline 12 & $19 \cdot 1$ & $16 \cdot 2$ & $14 \cdot 8$ & $13 \cdot 7$ & $18 \cdot 4$ & 16.9 & $20 \cdot 6$ & $16 \cdot 6$ & $19 \cdot 0$ & $16 \cdot 4$ & $18 \cdot 8$ & $14 \cdot 0$ \\
\hline L. 1 & $21 \cdot 1$ & $15 \cdot 7$ & $16 \cdot 8$ & $14 \cdot 0$ & $21 \cdot 0$ & $17 \cdot 0$ & $20 \cdot 0$ & $15 \cdot 6$ & $22 \cdot 2$ & $16 \cdot 3$ & $21 \cdot 3$ & $13 \cdot 6$ \\
\hline 2 & $20 \cdot 7$ & $14 \cdot 7$ & $17 \cdot 8$ & $13 \cdot 8$ & $21 \cdot 7$ & $15 \cdot 0$ & $21 \cdot 1$ & $14 \cdot 7$ & $16 \cdot 7$ & $17 \cdot 2$ & $22 \cdot 5$ & $14 \cdot 0$ \\
\hline 3 & $22 \cdot 0$ & $14 \cdot 7$ & $17 \cdot 9$ & $12 \cdot 7$ & $21 \cdot 7$ & $15 \cdot 0$ & $21 \cdot 0$ & $13 \cdot 9$ & $17 \cdot 7$ & $16 \cdot 0$ & $22 \cdot 3$ & $14 \cdot 9$ \\
\hline 4 & $25 \cdot 0$ & $17 \cdot 0$ & $19 \cdot 5$ & $11 \cdot 6$ & $23 \cdot 2$ & $16 \cdot 5$ & $22 \cdot 1$ & $14 \cdot 2$ & $18 \cdot 3$ & $16 \cdot 0$ & $23 \cdot 0$ & $15 \cdot 3$ \\
\hline 5 & $28 \cdot 4$ & $18 \cdot 0$ & $22 \cdot 4$ & $10 \cdot 6$ & 24.4 & $18 \cdot 0$ & $24 \cdot 0$ & $13 \cdot 7$ & $19 \cdot 1$ & $14 \cdot 7$ & $26 \cdot 0$ & $17 \cdot 9$ \\
\hline 6 & & & $23 \cdot 4$ & $11 \cdot 5$ & & & & & & & & \\
\hline S.1 & $35 \cdot 0$ & $14 \cdot 2$ & $23 \cdot 4$ & $11 \cdot 8$ & $30 \cdot 2$ & $10 \cdot 0$ & $22 \cdot 8$ & $8 \cdot 3$ & $27 \cdot 1$ & $12 \cdot 2$ & $31 \cdot 0$ & $14 \cdot 0$ \\
\hline
\end{tabular}

fact that the zone of necrosis coincided exactly with the "critical zone" defined in this study.

Wolman (1965), in collaboration with Hardy, describes the post-mortem appearances of the spinal cord in ninety-five cases of traumatic paraplegia and stresses the significance of ischaemia. In at least a third there was central necrosis attributable to this factor. In others there was oedema of the cord and raised intramedullary pressure.

While the factor or factors responsible for neuronal degeneration and paraplegia are not clear, impairment of the circulation is of undoubted and possibly prime significance. Romanes (1965) observed that "it is obvious from the short period of absolute anoxaemia which the spinal cord can survive without permanent damage, that there is little possibility for the effective enlargement of a collateral circulation, and that survival or death of spinal tissue following injury to the vascular supply must depend on the adequacy of the channels remaining intact. It is of some importance therefore to determine which of the features of this blood supply are standard and which are liable to marked variation before attempting to predict the results of injury to different parts of this system."

The studies reported here have defined the standards and the variables, and have given a clear indication of the presence of a critical vascular zone of the spinal cord between the fourth and the ninth thoracic vertebrae. 


\section{SUMMARY AND CONCLUSIONS}

1. A high incidence of paraplegia following operations for the correction of severe scoliosis in adults led to an investigation of the normal blood supply of the human spinal cord.

2. This entailed three methods of study: micro-dissection of the vessels of the spinal cord in thirty-five cadavers; radiological measurements of the spinal canal in fifty healthy subjects; and a study of the macerated spinal column in six adult cadavers.

3. The blood supply of the spinal cord is shown to be least rich, and the spinal canal narrowest, from the T.4 to approximately the T.9 vertebral level. This is named the critical vascular zone of the spinal cord, the zone in which interference with the circulation is most likely to result in paraplegia.

I would like to express my gratitude to a number of persons and institutions for help with this research-in the University of Pretoria, to Professor H. W. Snyman, Dean of the Faculty of Medicine; to Professor I. S. de Wet, Head of the Department of Orthopaedics; to Professor D. P. Knobel, Head of the Department of Anatomy; to $\mathrm{Mr} \mathrm{H}$. Brüne and Miss H. Coetzee, Technical and Photographic Sections, Department of Anatomy; and to Mrs T. Teuben, Photographic Section, Department of Orthopaedics; in the H. F. Verwoerd Hospital, Pretoria, to Dr W. H. F. Kenny and Dr E. van Wyngaardt, Superintendent and Assistant Superintendent; and to the National Council for the Care of Cripples, the South African Institute for Medical Research, the Ethical Drugs

Association Foundation, and the Louw van Wyk Orthopaedic Trust.

\section{REFERENCES}

Bolton, B. (1939): The blood supply of the human spinal cord. Journal of Neurology and Psychiatry, N.S. 2, 137.

Di Chiro, G., Fried, L. C., and Doppman, J. L. (1970): Experimental spinal cord angiography. British Journal of Radiology, 43, 19.

Dommisse, G. F., and Enslin, T. B. (1970): Hodgson's circumferential osteotomy in the correction of spinal deformity. Journal of Bone and Joint Surgery, 52-B, 778.

DWYer, A. L. (1972): Personal communication.

FeEney, J. F., Jun., and Watterson, R. L. (1946): The development of the vascular pattern within the walls of the central nervous system of the chick embryo. Journal of Morphology, 78, 231.

Hodgson, A. R. (1966): Personal communication.

Hodgson, A. R. (1972): Personal communication.

KADYI, H. (1889): Ueber die Blutgefässe des menschlichen Rückenmarkes. Lemberg, Poland: Gubrynowicz and Schmidt.

Lazorthes, G., Gouaze, A., Zadeh, J. O., Santini, J. J., Lazorthes, Y., and Burdin, P. (1971): Arterial vascularisation of the spinal cord. Recent studies of the anastomotic substitution pathways. Journal of Neurosurgery, 35, 253.

MacEwen, G. D. (1972): Personal communication.

Romanes, G. J. (1965): The arterial blood supply of the human spinal cord. Paraplegia, 2, 199.

Sokoloff, L. (1961): Local cerebral circulation at rest and during altered cerebral activity induced by anesthesia or visual stimulation. In Regional Neurochemistry, p. 107. Edited by S. S. Kety and J. Elkes. London: Pergamon Press.

Stephens, R. B., and Stilwell, D. L. (1969): Arteries and Veins of the Human Brain, p. 6. Springfield, Illinois: Charles C. Thomas.

Suh, T. H., and Alexander, L. (1939): Vascular system of the human spinal cord. Archives of Neurology and Psychiatry, 41, 659.

TuRnbull, I. M. (1971): Microvasculature of the human spinal cord. Journal of Neurosurgery, 35, 141.

Wolman, L. (1965): The disturbance of circulation in traumatic paraplegia in acute and late stages. Paraplegia, 2, 213.

Woollam, D. H. M., and Millen, J. W. (1958): In Discussion on vascular disease of the spinal cord. Proceedings of the Royal Society of Medicine, 51, 540.

VOL. $56 \mathrm{~B}$, NO. 2, MAY 1974 